\title{
Physicians' Estimates of Electronic Prescribing's Impact on Patient Safety and Quality of Care
}

\author{
Eija Kivekäs $^{1}$ Santtu Mikkonen ${ }^{2}$ Elizabeth Borycki ${ }^{3}$ \\ ${ }^{1}$ Department of Health and Social Management, University of Eastern \\ Finland, Kuopio, Finland \\ ${ }^{2}$ Department of Applied Physics, University of Eastern Finland, \\ Kuopio, Finland \\ ${ }^{3}$ School of Health Information Science, University of Victoria, \\ Victoria, British Columbia, Canada \\ ${ }^{4}$ Information Technology and Services, Tieto Ltd., Kuopio, Finland
}

\author{
Sami Ihantola ${ }^{4}$ Kaija Saranto ${ }^{1}$
}

Address for correspondence Eija Kivekäs, MSc, Department of Health and Social Management, University of Eastern Finland, Kuopio Campus, Kuopio 70211, Finland (e-mail: eija.kivekas@uef.fi).

ACI Open 2018;2:e30-e40.

Abstract

Keywords

- safety

- quality

- electronic prescribing

- technology

acceptance model
Background Electronic prescribing (e-prescribing) is a potentially important intervention that can be used to reduce errors. It provides many potential benefits over handwritten medication prescriptions, including standardization, legibility, audit trails, and decision support. Electronic health record (EHR) and e-prescribing systems may greatly enhance communication and improve the quality and safety of care.

Objectives Our aim is to investigate physician's opinions about the influence of electronic prescriptions on patient safety and quality of care.

Methods This study extends the technology acceptance model to analyze the acceptance of e-prescribing and adds an understanding of what kind of impact the external variables (patient identification and the interoperability of applications) have on physicians' individual work performance (i.e., patient safety and quality of care). The empirical analysis uses data from surveys conducted in 2012 and 2014 in Finland. The participants were physicians, and e-prescribing was the only method that could be used for prescribing medication when these studies were conducted.

Results Physicians' perceived usefulness of e-prescribing was significantly associated with patient safety and quality of care. The interoperability of an EHR had a significant effect on both the perceived ease of use and perceived usefulness of e-prescribing. The findings show that experience with an e-prescribing system has a positive effect on participants' perceived ease of use and perceived usefulness of e-prescribing.

Conclusion This study highlights potential safety and efficiency benefits associated with integrated health information technology in health care. The perceived usefulness of e-prescribing affected physicians' opinions on patient safety and quality of care.

\section{Introduction}

Electronic prescribing (e-prescribing) systems used in conjunction with decision support are increasingly being adopted in primary care and hospital settings around the world to reduce prescribing errors. ${ }^{1-3}$ These systems elim-

received

April 8, 2018

accepted

May 6, 2018
DOI https://doi.org/

10.1055/s-0038-1660464.

ISSN 0000-0000. inate the problem of illegible handwriting, increase the accuracy and completeness of information, and improve response times and the continuity of patient care. Many safety problems arise from poor communication between and across the professions (e.g., physicians, nurses, and pharmacist groups) and departments (e.g., pharmacy and
License terms

Stuttgart · New York

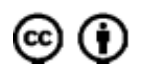


medicine). ${ }^{4,5}$ Information technology (IT), particularly electronic health record (EHR) and e-prescribing systems, have great potential to enhance communication and improve the quality and safety of care. ${ }^{6,7}$ However, some studies suggest the existence of serious problems and deficiencies associated with e-prescribing, which may significantly hinder the efficiency of EHR use and physicians' routine work, ${ }^{8,9}$ such as creating usability problems and introducing new error types. ${ }^{9}$ This article's focus is on physicians' perception of patient safety and quality of care (PSQ).

In this article, our aim is to investigate the influence of electronic prescription (e-prescription) on PSQ on physician's work as e-prescribing is used in primary health care settings and in a university hospital district. The first survey took place in 2012 when the e-prescribing system was initially introduced in Finland, followed by the second survey conducted in 2014, when the system was implemented nationally. Our work contributes to the research literature by exploring the relationship between key concepts (i.e., PSQ) as well as the technology acceptance model (TAM) and the interoperability of the EHR, e-prescribing, and the national Pharmaceutical Database.

\section{Conceptual Framework}

The conceptual framework that forms the basis of this study is the TAM. The TAM model was developed based on existing behavioral intention models in the social sciences: the theory of reasoned action ${ }^{10}$ and theory of planned behavior. ${ }^{11,12}$ The TAM model is based on two fundamental beliefs, namely systems' perceived usefulness (PU) and perceived ease of use (PEoU). ${ }^{13}$ Davis defined PU as "the degree to which a person believes that using a particular system would enhance his or her job performance." PEoU can be defined as "the degree to which a person believes that using a particular system would be free of effort."13 These beliefs determine an individual's attitude toward the use, behavioral intention, and actual usage of information systems. The TAM model posits a relationship (1) between users' perceptions of technology and acceptance and (2) between acceptance and actual use.

Today, the TAM model is widely used as a conceptual framework in studies of the acceptance of various health information technologies (HITs). Prior research involving the TAM model explored the relationships between TAM concepts and the impact of national cultural differences, ${ }^{14}$ perceived importance of data security, ${ }^{15}$ a person's privacy concerns, ${ }^{16}$ and perceived threat to professional autonomy. ${ }^{17,18}$ Additionally, PSQ were studied and noted as having a relationship with concepts described in the TAM model. ${ }^{19}$ Most studies have focused on health professionals' behavioral intention to use health care technology. ${ }^{20,21}$ Holden and Karsh highlighted the necessity of contextualizing the TAM model for health care settings and suggested that this could be done by differentiating between performance benefits accruing at the personal and group levels, focusing on health care outcomes, and allowing for different sources of social influences. ${ }^{12}$ For example, Sun et al extended IT usage models to include the role of IT's perceived work compat- ibility in shaping users' IT usage intention, usage, and performance in a work setting. ${ }^{22}$ The authors suggested that it was important to contextualize IT usage within a work setting to maximize its power in organizations.

HIT has been shown to potentially improve PSQ. ${ }^{3,23,24}$ Quality of health care can be defined as doing the right thing at the right time and in the right way to achieve the best possible results for a patient. ${ }^{23}$ In this study, patient safety means the continuous identification, analysis, and management of patient-related risks and incidents to minimize harm to patients. ${ }^{6,23}$ One of the main HIT issues is the heterogeneity of available systems, ${ }^{5}$ interoperability and adaptation have to be introduced into the model through compliance with technological and health-oriented standards. ${ }^{5,25,26}$ For instance, an e-prescribing system that helps physicians enter orders on a computer could help prevent medication errors. $3,27,28$

In Finland, e-prescriptions are stored in a centralized database, the Prescription Centre. The Prescription Centre is one part of the National Archive of Health Information (also called Kanta services). In addition to e-prescriptions, Kanta services comprise the Pharmaceutical Database and the Patient Data Repository. The Pharmaceutical Database includes information necessary for prescribing and dispensing, such as the process of administering medication and reimbursement status. ${ }^{29,30}$

Interoperability issues may arise if patient care requirements, clinical processes, and administrative requirements are not adequately addressed. ${ }^{19,31}$ Interoperability refers to the ability of various information systems and software applications to communicate, exchange data, and use information that has been exchanged. ${ }^{32}$ Definitions for e-prescriptions contain the use cases, requirements and data contents of the pharmacy system, Patient Records Archive, and HL7 definitions. ${ }^{29}$ Integration is a combination of diverse application entities into a relationship, which functions as a whole. This study attempts to use a conceptual framework for e-prescribing, patient safety, and quality of care in physicians' work and to illustrate the usefulness of e-prescription in improving the quality and safety of care., ${ }^{6,7}$ This study extends the TAM model to analyze the acceptance of e-prescribing and adds an understanding of what kind of impact the external variables, patient identification, and interoperability of applications (i.e., interoperability between the EHR, e-prescribing, and the pharmaceutical database) have on physicians' individual work performance. The difference between previous studies and this study is it focuses on e-prescribing's impact on physicians' perception of PSQ rather than on the intention to use or usage of a system. PSQ could be viewed as measures of the usefulness of a system, but this study uses PSQ as estimates for e-prescribing's usefulness.

\section{Research Model Hypotheses}

The present study hypothesizes a model for predicting physicians' attitudes toward using an e-prescribing system as one for providing safer care. The study seeks to assess the impact of an e-prescribing system on PSQ as well as assess effects 
between PU and PEoU and external variables, including the interoperability of an EHR system and patient identification.

A gap between the postulated and objectively demonstrated benefits of electronic health (e-health) systems, including e-prescribing, was found in Black et al's systematic review that assessed the impact of an e-health system on perceived patient safety. ${ }^{33}$ Davies et al suggested a potential for deterioration rather than improvement in perceived patient safety and safety attitudes among staff with the introduction of eprescribing. ${ }^{28}$ The authors of the study found problems with systems' usability, nonstandardized implementation, and competence assessment strategies. They conducted a crosssectional study, which targeted all hospital staff involved in the care of surgical patients in southwestern England. ${ }^{28}$ Similar results have been found with e-prescribing systems' usability in Finland and Sweden. ${ }^{8,24,34}$

Our research model ( - Fig. 1) seeks to assess and explain the impact of an e-prescribing system on PSQ on physicians' individual work performance. Two factors, patient safety and quality of care, will reveal the consequences of e-prescription as assessed by physicians. Two external variables, EHRs' interoperability (iEHR) and patient identification (ID), highlight the consequence of using the technology. The architecture of national social and health services in Finland describes the sector's common procedures, data contents, and data system services. ${ }^{29}$ Physician uses the information by accessing patients' records, where patients' medication list, prescribing history, and known medication allergies are documented, and patient records to prescribing are accessible. PU and PEoU, which are two factors in the TAM, emphasize the importance of physicians' opinions on the use of e-prescribing software in their work.

PSQ are the focus of this study. The original TAM was developed to predict users' organizational information system use. In this study, we are seeking to understand the kind of impact PU and PEoU have on physicians' work performance, including PSQ. Based on previous studies, seven hypotheses were identified.

\section{Perceived Usefulness of Electronic Prescribing Systems}

Davis linked PU with outcome expectations, instrumentality, and extrinsic motivation. ${ }^{13}$ PU refers to one's belief that using a technology will lead to desirable outcomes, usually involving an increase in personal effectiveness or productivity. ${ }^{13}$ An IT system's usefulness was found to be significant for users' acceptance in health care-related TAM model studies. ${ }^{16,19,35}$ For example, participants believed that the new system could enhance job performance or improve work quality. ${ }^{14,35}$ However, Sicotte et al found that one weakness of the TAM model's factors (PU, PEoU) was they did not predict new technology use among physicians. ${ }^{36}$ Regardless of the weakness of the TAM model's factors, using an e-prescribing system is expected to improve PSQ on medication prescribing.

Thus, we hypothesized:

H1. e-Prescribing's PU is positively associated with physicians' perceptions of PSQ.

\section{Perceived Ease of Use of Electronic Prescribing Systems}

Studies on TAM model use in health care found a significant positive influence of PEoU on PU. ${ }^{12,36}$ In health care, ease of use, like time efficiency, would also be relevant. ${ }^{37}$ If systems are easy to use and suitable for integration into daily work, they deliver adequate performance in most cases. ${ }^{37}$ This finding is relevant, and it indicates that e-health applications would benefit physicians. ${ }^{12,19,36}$ Contradictory reporting has been found in which there was no significant association between PEoU and actual use of information systems. ${ }^{19,38}$ PEoU could indirectly influence technology adoption through PU and should be considered a determining factor in technology acceptance. ${ }^{19}$ Therefore, improving the usability of e-health systems is important. We hypothesized:

H2. e-Prescribing's PEoU is positively associated with PSQ. H3. e-Prescribing's PEoU is positively associated with PU.

\section{Interoperability of the Electronic Health Record System and Patient Identification}

EHR systems are computer systems that allow one to create, store, edit, and retrieve patient charts on a computer. ${ }^{32}$ These systems facilitate the organization and rapid retrieval of information by serving as digital repositories for physicians' notes and laboratory results as well as patients' medications, allergies, and essential sociodemographic and contact data. ${ }^{12}$ Interoperability has been defined as the ability of different IT systems and software applications to communicate, exchange data, and use information that has been exchanged. ${ }^{32}$ Interoperability is no longer alone a technological option; it is a

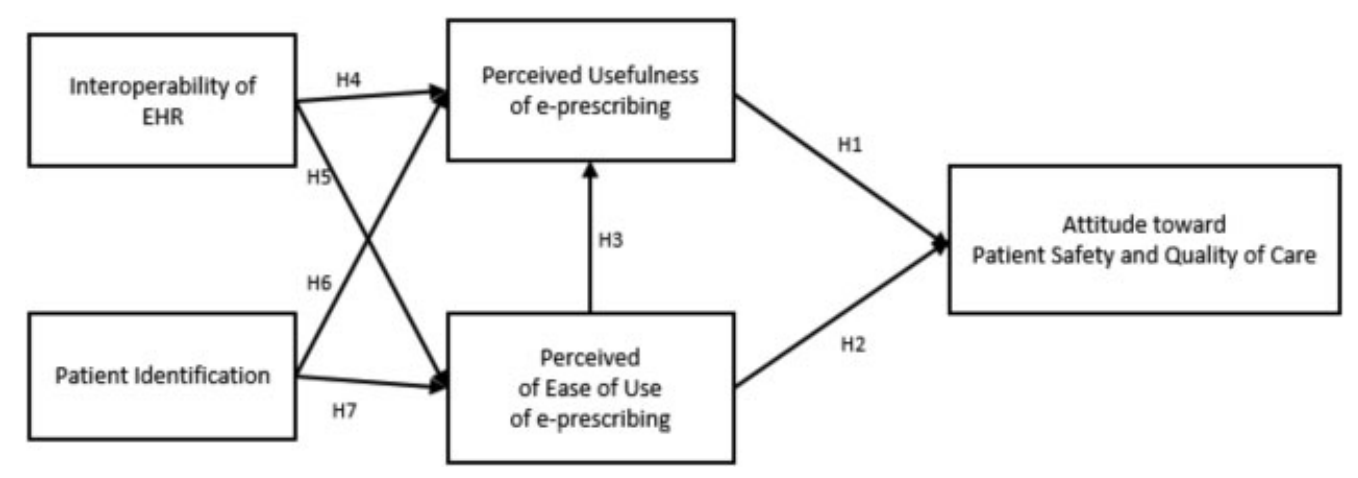

Fig. 1 Research model for predicting e-prescribing's influence with patient safety and quality of care. 
fundamental requirement for delivering effective care and ensuring the health and well-being of patients. ${ }^{39}$ Therefore, our hypotheses are as follows:

H4. An EHR system's interoperability is positively associated with the PU of e-prescribing.

H5. An EHR system's interoperability is positively associated with the PEoU of e-prescribing.

Recording a patient's demographic, treatment, and outcome data makes it possible to assess the results of changes to treatments or to the organization of care. ${ }^{12}$ Consequently, the failure to correctly identify patients continues to result in medication errors, testing errors, and wrong-person procedures. The ultimate goal is to accurately identify the patient and link all related information to the individual within and across systems. ${ }^{31}$ Therefore, we hypothesize:

H6. Patient identification is positively associated with the PU of e-prescribing.

H7. Patient identification is positively associated with the PEoU of e-prescribing.

\section{Data Collection and Analysis}

The empirical analysis uses data from surveys conducted in 2012 and 2014. The participants were all physicians who worked in primary health care and in a university hospital district. e-Prescribing was the only method that could be used for prescribing medication in Finland at the time of these studies. e-Prescriptions are sent electronically from a physician's office to a central database (i.e., the National Prescription Center). Pharmacies also have electronic access to prescriptions. The Finnish e-prescribing system uses a pull model; ${ }^{40}$ it allows any authorized pharmacy to retrieve prescription information into its system for processing.

At the time of the data collection (2012 and 2014), the eprescribing system had been used for more than 1 year and all physicians had experience with e-prescribing. The first study (2012) took place in two primary health care organizations ( $n=69 / 269,26 \%$ ). These primary health care organizations were the first in Finland to implement the e-prescribing system in 2010 and 2011. The second study (2014) took place in the university hospital district area, including a university hospital and primary health care enterprises $(n=131 / 1,135$, $12 \%)$. The university hospital district area was among the last in Finland to implement the e-prescribing system in 2013. The two studies had different participants due to their affiliations in primary care and hospital settings. However, participants in both studies had a little more than 1 year of experience with the e-prescribing system. A questionnaire was used as a collection method to obtain an overview of the participants' status.

A questionnaire was developed following a review of previously published questionnaires, ${ }^{24,41}$ prior research, and studies involving the TAM model. The study questionnaire was pretested twice in 2012 and 2014 by clinicians, senior health care officials, and two faculty members. One faculty member had a background in health and human services informatics and the other in pharmacology. The pretest allowed the researchers to identify confusing or redundant items through discussion with the individuals who were in the pretest. In this study, e-prescribing was investigated by utilizing a combination of questions inspired by the TAM model (i.e., $n=18$ items), questions from a survey by Hellström and her colleagues (i.e., $n=10$ items), ${ }^{24}$ and structured questions collected by a 5-point Likert-type scale where 1 "strongly disagree" and 5 "strongly agree." Seven structured questions were used to collect demographic data.

Physicians were invited to complete the surveys by email. All physicians in the organizations received an email with a hyperlink to the survey ( $n=269$ in 2012, $n=1,135$ in 2014). The e-mail also included information about the purpose of the study and the researchers. No incentives were offered for participation. The web-based survey was available for completion for a period of 2 weeks and subsequently for an additional week after two reminder emails were sent inviting physicians to participate in the survey study. The first survey took place between September and October 2012, and the second study took place between April and May 2014.

This article provides a comparative analysis of how e-prescribing influenced physicians' work and how TAM factors and external variables correlate with PSQ. The TAM suggests that external variables indirectly determine one's attitude toward technology acceptance by influencing PU and PEoU. In our study, PSQ (-Table 1), the iEHR, and ID ( formulated by exploratory factor analysis. The model's validity was tested with the Kaiser-Meyer-Olkin test and Bartlett's test of sphericity, and all factors presented here fulfilled the tests' assumptions. Additionally, Cronbach's $\alpha$ values were calculated for the factors to test the scale's reliability. The $\alpha$ values were in

Table 1 Factor loading of patient safety and quality of care

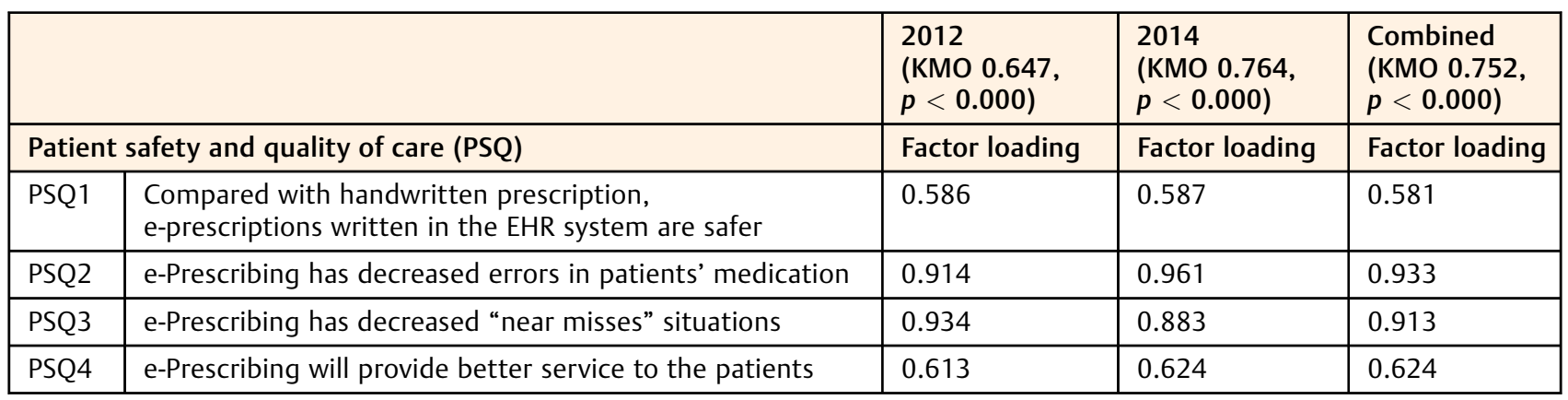

Abbreviations: EHR, electronic health record; KMO, Kaiser-Meyer-Olkin. 
Table 2 Factor loading of external variables (iEHR and ID)

\begin{tabular}{|c|c|c|c|c|}
\hline & & $\begin{array}{l}2012 \\
(\text { KMO 0.647, } \\
p<0.000)\end{array}$ & $\begin{array}{l}2014 \\
(\text { KMO 0.764, } \\
p<0.000)\end{array}$ & $\begin{array}{l}\text { Combined } \\
\text { (KMO 0.752, } \\
p<0.000 \text { ) }\end{array}$ \\
\hline & & Factor loading & Factor loading & Factor loading \\
\hline \multicolumn{5}{|c|}{ Interoperability of EHR system (iEHR) } \\
\hline iEHR1 & $\begin{array}{l}\text { The EHR system clearly displays the } \\
\text { basic information for each medication }\end{array}$ & 0.998 & 0.706 & 0.765 \\
\hline iEHR2 & $\begin{array}{l}\text { The EHR system clearly displays the } \\
\text { price for each medication }\end{array}$ & 0.588 & 0.748 & 0.711 \\
\hline iEHR3 & $\begin{array}{l}\text { The EHR system clearly displays the } \\
\text { medicine package for each medication }\end{array}$ & 0.438 & 0.695 & 0.629 \\
\hline iEHR4 & The EHR supports the e-prescribing & 0.421 & 0.405 & 0.357 \\
\hline \multicolumn{5}{|c|}{ Patient Identification (ID) } \\
\hline ID1 & $\begin{array}{l}\text { When e-prescribing medication, the EHR system clearly } \\
\text { displays the personal identity code of the current patient }\end{array}$ & 0.950 & 0.950 & 0.963 \\
\hline ID2 & $\begin{array}{l}\text { When e-prescribing medication, the EHR system clearly } \\
\text { displays the name of the current patient }\end{array}$ & 0.972 & 0.970 & 0.959 \\
\hline
\end{tabular}

Abbreviation: KMO, Kaiser-Meyer-Olkin.

the range of 0.65 to 0.96 , which indicates adequate consistency. ${ }^{42}$ The survey data were combined for statistical analysis, and when the survey was completed, it was a background variable.

An exploratory factor analysis was also conducted with PU and PEoU variables, and it revealed some variation between 2012 and 2014 data. Despite some slight variation in the PU and PEoU factor loadings between the two years (-Table 3), the TAM's two main factors were kept in the initial structure.

Additionally, the researcher tested the effect of background variables (i.e., gender, age, setting, date of graduation, experience with e-prescribing and EHR, personal computing (PC) skills, and years the survey was taken) on the revealed significant association with the independent variables. To ensure content validity, the measurement items used to capture the theoretical construct were adopted from scales validated in previous health informatics research. ${ }^{13,24,36,41}$ Measures of the iEHR and ID were adapted from the national strategy of health informatics ${ }^{43}$ and the Healthcare Information and Management Systems Society. ${ }^{31}$

First, we conducted descriptive analyses to explore the demographic and theoretical data distribution. Next, we performed a path analysis using the maximum likelihood method of parameter estimation to test direct and indirect impacts on the extended TAM model. In the first step, we entered dimensions pertaining to the TAM (PU and PEoU). Then, two other dimensions, namely iEHR and ID, were added to the research model to improve its predictive power. All associations with predictors and PSQ were hypothesized as direct in iEHR and ID. We tested the influence of experience and demographic characteristics on physicians' attitudes toward the PSQ to detect potential modifying effects.

To evaluate the effectiveness of our research model, we employed an analysis of covariance (ANCOVA) to test the hypothesis that the research model will demonstrate physicians' perception of the e-prescribing system's impact on PSQ and test how the extended research model works with these data. The final model presented in the article includes only the significant predictors of PSQ. All statistical analyses were performed with SAS 21 (IBM, Amok, NY) and AMOS. A $p$-value of 0.05 was set as the level of statistical significance.

\section{Results}

Most participants ( $n=139,70 \%)$ were female. The participants' mean age was 44.57 years (median $=46$ years). About two-thirds of the participants $(n=123,66 \%)$ worked in primary care at the time of the study. The participants' mean experience with an EHR system was 7.82 years (median $=7$ years), and half of the participants ( $n=115,59 \%)$ had more than 1 year of experience with e-prescribing technology. For a full overview of the participants' demographic information, see - Table 4.

In general, the participants used the e-prescribing system daily, and over half ( $n=121,62 \%)$ used e-prescribing more frequently than five times per day. Over half of the participants ( $n=121,61 \%$ ) self-evaluated their PC skills as excellent.

- Table 5 shows the results from the ANCOVA model. PU had a significant association with PSQ and iEHR had a significant association with both PEoU and PU. The findings show that experience with an e-prescribing system has positive effects on the participants' PEoU and PU. The research also found that participants' PEoU and PU were higher when the participants worked in a hospital. The findings suggest that PEoU was higher for female respondents, and PSQ was higher for males. In the second measurement completed in 2014, the iEHR system had a positive effect on participants' PEoU. A weak but statistically significant association was found between the year of graduation and experience with an EHR system. This occurred 
Table 3 Measures of constructs, Cronbach's $\alpha$, and factory of items used by studies

\begin{tabular}{|c|c|c|c|c|}
\hline \multicolumn{2}{|c|}{ TAM model: theoretical constructs items } & $\begin{array}{l}2012 \\
\text { (Cronbach's } \alpha 0.97 \text {, } \\
\text { KMO 0.925, } \\
\text { sig. } 0.000 \text { ) }\end{array}$ & $\begin{array}{l}2014 \\
\text { (Cronbach's } \alpha 0.96 \text {, } \\
\text { KMO 0.925, } \\
\text { sig. 0.000) }\end{array}$ & $\begin{array}{l}\text { Combined } \\
\text { (KMO 0.929, } \\
\text { sig. } 0.000)\end{array}$ \\
\hline \multicolumn{2}{|c|}{ Perceived usefulness (PU) } & Factor loading & Factor loading & Factor loading \\
\hline PU1 & $\begin{array}{l}\text { Using e-prescribing improves } \\
\text { the quality of the work }\end{array}$ & 0.836 & 0.759 & 0.777 \\
\hline PU2 & $\begin{array}{l}\text { Using e-prescribing gives me greater } \\
\text { control over my work }\end{array}$ & 0.877 & 0.827 & 0.842 \\
\hline PU3 & $\begin{array}{l}\text { e-Prescribing enables me to accomplish } \\
\text { tasks more quickly }\end{array}$ & 0.895 & 0.825 & 0.881 \\
\hline PU4 & e-Prescribing supports critical aspects of my job & 0.835 & 0.788 & 0.798 \\
\hline PU5 & Using e-prescribing increases my productivity & 0.905 & 0.880 & 0.886 \\
\hline PU6 & $\begin{array}{l}\text { Using e-prescribing allows me to accomplish } \\
\text { more work than would otherwise be possible }\end{array}$ & 0.855 & 0.825 & 0.836 \\
\hline PU7 & $\begin{array}{l}\text { Using e-prescribing enhances my } \\
\text { effectiveness on the job }\end{array}$ & 0.970 & 0.883 & 0.912 \\
\hline PU8 & Using e-prescribing makes it easier to do my job & 0.927 & 0.795 & 0.849 \\
\hline PU9 & Overall, I find the e-prescribing useful in my job & 0.914 & 0.817 & 0.850 \\
\hline \multicolumn{2}{|c|}{ Perceived ease of use (PEoU) } & $\begin{array}{l}\text { (Cronbach's } \alpha 0.82 \text {, } \\
\text { KMO } 0.756 \text {, } \\
\text { sig. } 0.000 \text { ) }\end{array}$ & $\begin{array}{l}\text { (Cronbach's } \alpha 0.882 \text {, } \\
\text { KMO 0.837, } \\
\text { sig. } 0.000 \text { ) }\end{array}$ & $\begin{array}{l}\text { (KMO 0.848, } \\
\text { sig. } 0.000)\end{array}$ \\
\hline PeoU1 & Learning to operate e-prescribing is easy for me & 0.354 & 0.787 & 0.322 \\
\hline PeoU2 & I find e-prescribing cumbersome to use & 0.766 & 0.412 & 0.692 \\
\hline PeoU3 & $\begin{array}{l}\text { Interacting with the e-prescribing } \\
\text { is often frustrating }\end{array}$ & 0.859 & 0.316 & 0.783 \\
\hline PeoU4 & $\begin{array}{l}\text { I find it easy to get the e-prescribing } \\
\text { to do what I want it to do }\end{array}$ & 0.506 & 0.505 & 0.556 \\
\hline PeoU5 & $\begin{array}{l}\text { The e-prescribing is rigid and } \\
\text { inflexible to interact with }\end{array}$ & 0.668 & 0.719 & 0.671 \\
\hline PeoU6 & $\begin{array}{l}\text { It is easy for me to remember how to } \\
\text { perform tasks using the e-prescribing }\end{array}$ & 0.723 & 0.804 & 0.805 \\
\hline PeoU7 & $\begin{array}{l}\text { My interaction with the e-prescribing is } \\
\text { clear and understandable }\end{array}$ & 0.511 & 0.564 & 0.506 \\
\hline PeoU8 & $\begin{array}{l}\text { I find it takes a lot of effort to become } \\
\text { skillful at using the e-prescribing }\end{array}$ & 0.520 & 0.505 & 0.434 \\
\hline PeoU9 & Overall, I find the e-prescribing easy to use & 0.481 & 0.627 & 0.508 \\
\hline
\end{tabular}

Abbreviations: KMO, Kaiser-Meyer-Olkin; sig., significance.

when the participant was a newly qualified physician (i.e., under 4 years of experience as a physician) and their experience with using an EHR system was low; the iEHR system's importance was emphasized.

In statistics, a path analysis is used to describe direct dependencies among a set of variables. ${ }^{42}$ The paths in this model, denoted by one-headed arrows, contain assumptions of the directions of the associations between the variables. The results of the path analysis model testing the research model for predicting physicians' perception of e-prescribing's impact on PSQ are reported in -Fig. 2. A test of the structural model includes estimates for the path coefficients, which indicate the strengths of association between the independent variables. The path diagram supported a positive association for four of the hypotheses ( - Fig. 2). PU has a direct and positive effect on PSQ while PEoU has a direct positive effect on PU and an indirect effect on PSQ. iEHR and ID have a direct positive effect on PEoU, and they have an indirect effect on PU and PSQ. PEoU's direct effect on PSQ did not appear to be significant.

-Table 6 shows the path coefficient's direct, indirect, and total effects. This reflects an association in hypotheses $\mathrm{H} 1$, $\mathrm{H} 3, \mathrm{H} 5$, and $\mathrm{H} 7$ with a direct effect, while hypotheses H2, H4, and $\mathrm{H} 6$ yield an indirect effect.

\section{Discussion}

The aim of this study was to investigate the factors that can predict an e-prescribing system's influence on PSQ. The 
Table 4 Participants' profile $(n=200)$

\begin{tabular}{|c|c|c|c|c|}
\hline Characteristics & & $2012, n(\%)$ & $2014, n(\%)$ & $2012-2014, n(\%)$ \\
\hline \multirow[t]{2}{*}{ Gender $(n=198)$} & Male & $17(25)$ & $42(33)$ & $59(30)$ \\
\hline & Female & $52(75)$ & $87(67)$ & $139(70)$ \\
\hline \multirow[t]{3}{*}{ Age group (y, $n=200)$} & Under 34 & $18(26)$ & $54(41)$ & $72(36)$ \\
\hline & $35-54$ & $36(52)$ & 77 (59) & $113(56)$ \\
\hline & 55 or over & $15(22)$ & & $15(8)$ \\
\hline \multirow[t]{2}{*}{ Setting $(n=188)$} & Primary health care & $69(100)$ & $59(48)$ & $123(66)$ \\
\hline & Hospital & & $65(52)$ & $65(34)$ \\
\hline \multirow[t]{5}{*}{ Qualified as a physician (y, $n=199)$} & Under 4 & $11(16)$ & $14(11)$ & $27(14)$ \\
\hline & $5-14$ & $17(25)$ & $30(23)$ & $46(23)$ \\
\hline & $15-24$ & $8(12)$ & $33(25)$ & $45(23)$ \\
\hline & $25-34$ & $18(26)$ & $44(33)$ & $67(33)$ \\
\hline & 35 or over & $14(21)$ & $10(8)$ & $14(7)$ \\
\hline \multirow[t]{3}{*}{ Experience on EHR system $(y, n=160)$} & $<3$ & $14(22)$ & $26(27)$ & $40(25)$ \\
\hline & $4-9$ & $31(49)$ & $30(31)$ & $61(38)$ \\
\hline & $>10$ & $18(29)$ & $41(42)$ & $59(37)$ \\
\hline \multirow[t]{2}{*}{ Experience on e-prescribing (y, $n=195)$} & $\leq 1$ & $23(33)$ & $57(45)$ & $80(41)$ \\
\hline & $>1$ & $46(67)$ & $69(55)$ & $115(59)$ \\
\hline \multirow[t]{3}{*}{ e-Prescription per day $(n=194)$} & $\leq 5$ & $19(28)$ & $54(43)$ & $73(38)$ \\
\hline & $6-9$ & $23(35)$ & $33(26)$ & $56(29)$ \\
\hline & $>10$ & $25(37)$ & $40(31)$ & $65(33)$ \\
\hline \multirow[t]{2}{*}{ PC skills $(n=199)$} & Moderate or poor & $28(41)$ & $50(38)$ & 78 (39) \\
\hline & Excellent & $40(59)$ & $81(62)$ & $121(61)$ \\
\hline \multirow[t]{2}{*}{ Moment of surveys $(n=200)$} & 2012 & $69(26)$ & & $69(35)$ \\
\hline & 2014 & & $131(12)$ & $131(65)$ \\
\hline
\end{tabular}

Abbreviations: EHR, electronic health record; PC, personal computing.

Table 5 ANCOVA results (coefficients): PU, PEoU, PSQ, iEHR, and ID

\begin{tabular}{|c|c|c|c|c|c|c|c|c|c|c|}
\hline & \multicolumn{2}{|c|}{$\begin{array}{l}\text { Perceived of } \\
\text { usefulness } \\
(n=165)\end{array}$} & \multicolumn{2}{|c|}{$\begin{array}{l}\text { Perceived ease } \\
\text { of use } \\
(n=162)\end{array}$} & \multicolumn{2}{|c|}{$\begin{array}{l}\text { Patient safety } \\
\text { and quality } \\
\text { of care } \\
(n=160)\end{array}$} & \multicolumn{2}{|c|}{$\begin{array}{l}\text { Interoperability } \\
\text { of EHR } \\
(n=168)\end{array}$} & \multicolumn{2}{|c|}{$\begin{array}{l}\text { Patient } \\
\text { identification } \\
(n=168)\end{array}$} \\
\hline & B & Sig. & B & Sig. & B & Sig. & B & Sig. & B & Sig. \\
\hline Experience of e-prescribing & -0.365 & 0.012 & -0.265 & 0.046 & & & & & -0.260 & 0.090 \\
\hline Setting & -0.566 & 0.000 & -0.504 & 0.000 & & & & & & \\
\hline Interoperability of EHR & 0.186 & 0.022 & 0.353 & 0.000 & & & & & & \\
\hline Gender & & & -0.282 & 0.047 & 0.482 & 0.000 & & & & \\
\hline $2012-2014$ & & & -0.469 & 0.001 & & & 0.252 & 0.079 & & \\
\hline Perceived of usefulness & & & & & 0.571 & 0.000 & & & & \\
\hline Graduation & & & & & & & 0.663 & 0.042 & & \\
\hline Experience with EHR & & & & & & & -0.445 & 0.033 & & \\
\hline
\end{tabular}

Abbreviations: ANCOVA, analysis of covariance; ID, identification; iEHR, interoperability of electronic health record; PEoU, perceived of ease of use; PSQ, patient safety and quality of care; PU, perceived of usefulness; sig., significance. 


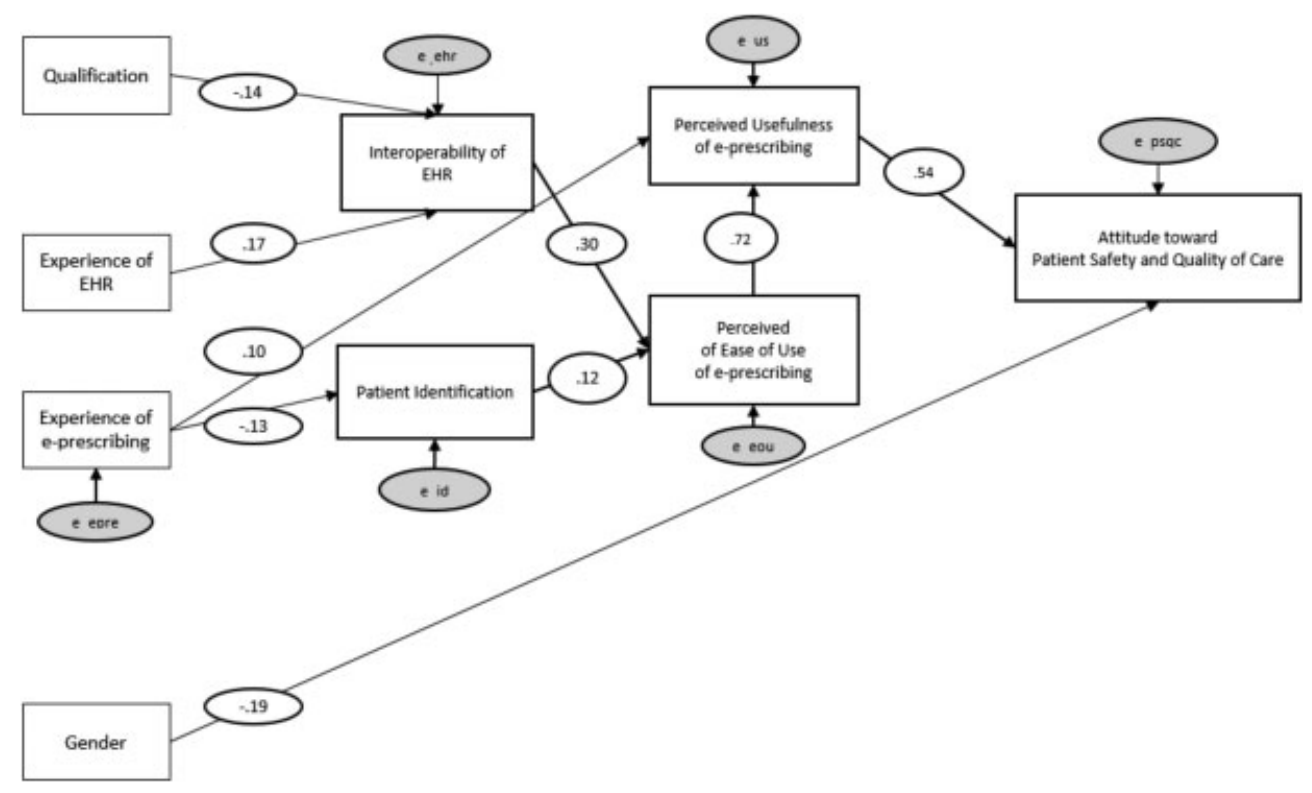

Fig. 2 Assessment of the research model (standardized solution).

study is founded on physicians' perceptions. The results illustrate interoperability is an essential requirement for HIT because of the need to integrate patient care across a variety of settings and providers. ${ }^{27,32}$ e-Prescribing has improved PSQ as expected. ${ }^{27,37}$ Physicians assessed e-prescribing as safer than handwritten prescribing, ${ }^{1,24}$ and it enabled them to provide better service. ${ }^{24}$ Some studies showed that e-prescribing systems cause fewer prescription errors compared with handwritten prescriptions. ${ }^{1,27}$ Experience with using e-prescribing, as hypothesized, is positively associated with PU and PEoU. Human factors, such as experience, influence the probability of e-prescribing errors in unintentionally entering incorrect information. The selection of an incorrect option or dosage by prescribers who are unfamiliar with the functionalities of a given e-prescribing system can endanger patient safety. ${ }^{1,44}$ The positive impact of e-prescribing and EHR systems is associated with e-prescribing, especially in hospital settings, and interoperability among systems is assessed as workable. ${ }^{12,32}$ National Kanta services comprise the Pharmaceutical Database and the Patient Data Repository, which improves physician's access to patients' medical information. ${ }^{29}$ EHR coverage reached $100 \%$ in public health care in 2010 , and the vast majority of private health care providers use EHR systems. ${ }^{30}$

Physicians' e-prescribing experiences are an important aspect of technology acceptance when it comes to the expected usefulness of e-prescribing and attitudes toward PSQ.,2,25 Our findings are similar to those reported in recent studies; PU is the most significant factor affecting physicians' intention to use IT. ${ }^{16,17}$ Our study differs from previous studies that have shown PEoU is a significant determinant of physicians' intention to use IT. ${ }^{12,16}$ The PEoU of e-prescribing had an indirect association on PSQ. ${ }^{21}$ A possible explanation might be that participants do not consider usability an important reason to use a technology. The serious implications of their actions for patients and the considerable responsibility they assume could mean that intention to use a technology might depend on factors related to improving PSQ and not on usability issues. ${ }^{20}$ Furthermore, Gururajan showed that the ease-of-use factor was not strongly significant in the health care domain when determining wireless technology adoption. The health care environment is complex, sensitive, and time critical. He assumed that these issues could be

Table 6 Effects of research model (hypothesis test results for the research model)

\begin{tabular}{|l|l|l|l|l|l|}
\hline Hypotheses & Path & Total & Direct & Indirect & Results \\
\hline $\mathrm{H} 1$ & $\mathrm{PU} \rightarrow \mathrm{PSQ}$ & 0.542 & 0.542 & 0.000 & Supported \\
\hline $\mathrm{H} 2$ & $\mathrm{PEoU} \rightarrow \mathrm{PSQ}$ & 0.392 & 0.000 & 0.392 & No supported \\
\hline $\mathrm{H} 3$ & $\mathrm{PEoU} \rightarrow \mathrm{PU}$ & 0.724 & 0.724 & 0.000 & Supported \\
\hline $\mathrm{H} 4$ & $\mathrm{iEHR} \rightarrow \mathrm{PU}$ & 0.216 & 0.000 & 0.216 & No supported \\
\hline $\mathrm{H} 5$ & $\mathrm{iEHR} \rightarrow \mathrm{PEoU}$ & 0.298 & 0.298 & 0.000 & Supported \\
\hline $\mathrm{H} 6$ & $\mathrm{ID} \rightarrow \mathrm{PU}$ & 0.085 & 0.000 & 0.085 & No supported \\
\hline $\mathrm{H} 7$ & $\mathrm{ID} \rightarrow \mathrm{PEoU}$ & 0.118 & 0.118 & 0.000 & Supported \\
\hline
\end{tabular}

Abbreviations: ID, identification; iEHR, interoperability of electronic health record; PEoU, perceived of ease of use; PSQ, patient safety and quality of care; PU, perceived of usefulness. 
some of the reasons why the TAM model did not perform as expected in health care settings. ${ }^{45}$ It has been shown that $24 \%$ of prior studies did not find a significant relationship between PEoU and behavioral intention. ${ }^{38}$

Interestingly, the results revealed that newly qualified physicians, who had little experience with EHRs, found the support of the interoperability of the EHR helpful. Physicians' resistance to IT such as EHRs has been reported in other studies. ${ }^{18,35}$ This research highlights the importance of attitudinal factors and cognitive instrumental processes where the medical professionals' adoption and utilization of health information systems with technology acceptance is concerned. Newly qualified physicians may use the information systems without prejudice. Prior research has shown that computer skills and young age were positively associated with technology adoption. ${ }^{16}$ IT acceptance studies in the health care field have reported that higher levels of HIT experience led to a better understanding of where the components and functions of HIT were useful in daily routines. ${ }^{12,32,44}$ These facts did not emerge with participants who have little experience with using EHRs in this study. This phenomenon could have arisen as the first sign of digital natives who think highly of the interoperability of technology.

The interoperability of applications (i.e., EHR, e-prescribing, and the pharmaceutical database) and technological solutions as patient identification factors had an association with PEoU and an indirect association with PU. Technological solutions could be seen as relevant in physicians' work processes, whereas PSQ may be considered the benefits of electronic development. ${ }^{12,19,32}$ In this study, e-prescribing was a positive example of HIT development, and the PU of eprescribing had a clear association with PSQ.

A path analysis was used to analyze the complex association between different factors. Methods such as ANCOVA and path analysis are suitable for research on e-prescribing systems, where the objects of the research are multidimensional. Path analysis made it possible to investigate effects among complex factors and their structures describing PSQ. By selecting PSQ as dependent variables in our extended model, the importance of developing an e-prescribing system has been explained. ${ }^{42,46}$ PSQ could also be considered usefulness, which is an independent variable in the TAM model.

This study highlights potential safety and efficiency benefits associated with integrated e-prescribing systems in health care ${ }^{6,9}$ used by physicians' during national implementation. The study examined physicians' experiences involving an e-prescribing system and their attitudes toward PSQ. The PU of e-prescribing had an association with PSQ. ePrescribing's PEoU had an indirect association with PSQ, whereas there was a direct effect on the PU of e-prescribing. The iEHR and ID had a direct effect on the PEoU of eprescribing. Physicians' EHR and e-prescribing experiences proved to be significant. ${ }^{1,2}$ The TAM model ${ }^{13}$ established the presence of associations between PEoU and PU and modified their association with PSQ. Previous research focusing on health IT acceptance has shown that the TAM model is suitable for predicting and explaining physicians' acceptance of e-prescribing ${ }^{36,41}$ and EHR systems. ${ }^{12,16}$

\section{Limitations and Future Directions}

Although the response rate was relatively small in the single surveys (26\% in 2012 and 12\% in 2014), the combined data made it possible to conduct statistical analyses and allowed a preliminary interpretation of the study results. This was possible because the settings in both facilities (primary care and a hospital) were the same regarding e-prescribing system implementation. The web surveys were based on physicians' willingness to participate. Users' responses may not be actual perceptions but rather the subjects' reports of their perceptions. Therefore, the physicians answering the web survey might have had a more positive attitude toward innovative technologies when compared with those who did not answer the survey. Analyzing why so many physicians did not choose to participate in the survey was beyond the limits of this study. The link to the web-based survey was sent to a contact person who forwarded the email to the physicians. He or she received an automatic reply if the email did not reach a physician. The electronic survey was opened by physicians 29 times in 2012 (11\%,29/269) and 63 times in $2014(6 \%, 63 / 1,135)$ without submitting the responses. Differences in gender groups may also be a source of bias in the study results. There was some association between female physicians and PEoU. In addition, male gender and PSQ were also associated with each other.

From a theoretical viewpoint, this study underlines the importance of instrumental and attitudinal factors on physicians' technology acceptance decisions. The TAM model's factors of attitude toward PSQ and PU appear to be predictive and mediating mechanisms in medical professionals' acceptance of health information systems such as e-prescribing. Many studies have looked at how the TAM model and extended TAM model could explain the acceptance of new technology. ${ }^{14-18}$ Future research may focus on determining whether the TAM model can also be used to explain the usefulness of a particular technology or "job performance" such as e-prescribing.

\section{Conclusion}

The study shows that the PU of an e-prescribing system was significantly associated with PSQ. The participants' opinions regarding e-prescribing and EHR systems were positive. The extended TAM model demonstrated that when experience with e-prescribing increased, the e-prescribing system's PEoU had an indirect effect on its PU and strengthened PSQ. Additionally, the research has focused on interoperability issues and improving the continuity of care to better understand technical effects and interoperability of work processes during HIT implementation.

Clinical Relevance Statement

- The PU of an e-prescribing system was significantly associated with PSQ.

- The interoperability of an EHR and patient identification had a direct association with e-prescribing's PEoU.

- This study highlights the importance of attitudinal factors and cognitive instrumental processes where 
the medical professionals' adoption and utilization of health information systems with technology acceptance is concerned. Newly qualified physicians may use the information systems without prejudice.

\section{Protection of Human and Animals Subjects}

This study did not collect patient data. The study was performed in compliance with the World Medical Association Declaration of Helsinki on Ethical Principles for Medical Research Involving Human Subjects, and the study received approval from the University of Eastern Finland Committee on Research Ethics (Statement 12/ 2012).

\section{Conflicts of Interest}

None declared.

\section{References}

1 Esmaeil Zadeh P, Tremblay MC. A review of the literature and proposed classification on e-prescribing: Functions, assimilation stages, benefits, concerns, and risks. Res Social Adm Pharm 2016; 12(01):1-19

2 Cresswell KM, Bates DW, Williams R, et al. Evaluation of mediumterm consequences of implementing commercial computerized physician order entry and clinical decision support prescribing systems in two "early adopter" hospitals. J Am Med Inform Assoc 2014;21(e2):e194-e202

3 Elliott RA, Lee CY, Hussainy SY. Electronic prescribing and medication management at a residential aged care facility: uptake by general practitioners and qualitative evaluation of the benefits and barriers. Appl Clin Inform 2016;7(01):116-127

4 Øvretveit J, Scott T, Rundall TG, Shortell SM, Brommels M. Improving quality through effective implementation of information technology in healthcare. Int J Qual Health Care 2007;19(05): 259-266

5 Ferrante S, Bonacina S, Pozzi G, Pinciroli F, Marceglia S. A design methodology for medical processes. Appl Clin Inform 2016;7(01): 191-210

6 Bates DW, Gawande AA. Improving safety with information technology. N Engl J Med 2003;348(25):2526-2534

7 Maillet É, Mathieu L, Sicotte C. Modeling factors explaining the acceptance, actual use and satisfaction of nurses using an Electronic Patient Record in acute care settings: an extension of the UTAUT. Int J Med Inform 2015;84(01):36-47

8 Kaipio J, Lääveri T, Hyppönen $\mathrm{H}$, et al. Usability problems do not heal by themselves: National survey on physicians' experiences with EHRs in Finland. Int J Med Inform 2017;97:266-281

9 Baysari MT, Hardie RA, Lake R, et al. Longitudinal study of user experiences of a CPOE system in a pediatric hospital. Int J Med Inform 2018;109:5-14

10 Fishbein M, Ajzen I. Belief, Attitude, Intention, and Behavior: An Introduction to Theory and Research. Reading, MA: AddisonWesley; 1975

11 Ajzen I. The theory of planned behavior. Organ Behav Hum Decis Process 1991;50:179-211

12 Holden RJ, Karsh BT. The technology acceptance model: its past and its future in health care. J Biomed Inform 2010;43(01):159-172

13 Davis FD. Perceived usefulness, perceived ease of use, and user acceptance of information technology. MIS Quarterly 1989;13 (03):319-340

14 Liu C, Cheng T. Exploring critical factors influencing physicians' acceptance of mobile electonic medical records based on the dual-factor model: a validation in Taiwan. BMC Med Inform Decis Mak 2015;15:1-12
15 Dünnebeil S, Sunyaev A, Blohm I, Leimeister JM, Krcmar H. Determinants of physicians' technology acceptance for e-health in ambulatory care. Int J Med Inform 2012;81(11): 746-760

16 Steininger K, Stiglbauer B. EHR acceptance among Austrian resident doctors. Health Policy Technol 2015;4:121-130

17 Walter Z, Lopez MS. Physician acceptance of information technologies: Role of perceived threat to professional autonomy. Decis Support Syst 2008;46:206-215

18 Ortega Egea JM, Román González MV. Explaining physicians' acceptance of EHCR systems: An extension of TAM with trust and risk factors. Comput Human Behav 2011;27:319-332

19 Abdekhoda M, Ahmadi M, Dehnad A, Noruzi A, Gohari M. Applying electronic medical records in health care: physicians' perspective. Appl Clin Inform 2016;7(02):341-354

20 Escobar-Rodrigues PM, Romero-Alonso M. Acceptance of E-prescriptions and automated medication-management systems in hospitals: an extension of the technology acceptance model. J Inf Syst 2012;26:77-96

21 Rho MJ, Choi IY, Lee J. Predictive factors of telemedicine service acceptance and behavioral intention of physicians. Int J Med Inform 2014;83(08):559-571

22 Sun Y, Bhattacherjee A, Ma Q. Extending technology usage to work settings: The role of perceived work compatibility in ERP implementation. Inf Manage 2009;46(06):351-356

23 Davis K, Doty MM, Shea K, Stremikis K. Health information technology and physician perceptions of quality of care and satisfaction. Health Policy 2009;90(2-3):239-246

24 Hellström L, Waern K, Montelius E, Åstrand B, Rydberg T, Petersson G. Physicians' attitudes towards ePrescribing-evaluation of a Swedish full-scale implementation. BMC Med Inform Decis Mak 2009;9(37):37

25 McLean S, Sheikh A, Cresswell K, et al. The impact of telehealthcare on the quality and safety of care: a systematic overview. PLoS One 2013;8(08):e71238

26 Boonstra A, Broekhuis M. Barriers to the acceptance of electronic medical records by physicians from systematic review to taxonomy and interventions. BMC Health Serv Res 2010;10(01): 231-248

27 Ammenwerth E, Schnell-Inderst P, Machan C, Siebert U. The effect of electronic prescribing on medication errors and adverse drug events: a systematic review. J Am Med Inform Assoc 2008;15(05): 585-600

28 Davies J, Pucher PH, Ibrahim H, Stubbs B. Impact of the introduction of electronic prescribing on staff perceptions of patient safety and organizational culture. J Surg Res 2017;212:222-228

29 Kanta. Electronic prescription. 2018. Available at: http://www. kanta.fi/en/web/ammattilaisille

30 Reponen J, Kangas M, Hämäläinen P, Keränen N. Use of Information and Communications Technology in Finnish Health Care in 2014. Helsinki: National Institute for Health and Welfare THL; 2015

31 HIMSS Board of Directors. Definition of Interoperability. 2013. Available at: http://www.himss.org/library/interoperability-standards/what-is-interoperability. Accessed May 13, 2017

32 Kuo MH, Kushniruk AW, Borycki EM. A comparison of national health data interoperability approaches in Taiwan, Denmark and Canada. Electr Healthc 2011;10(02):18-29

33 Black AD, Car J, Pagliari C, et al. The impact of eHealth on the quality and safety of health care: a systematic overview. PLoS Med 2011;8(01):e1000387

34 Kivekäs E, Enlund H, Borycki E, Saranto K. General practitioners' attitudes towards electronic prescribing and the use of the national prescription centre. J Eval Clin Pract 2016;22(05): 816-825

35 Yarbrough AK, Smith TB. Technology acceptance among physicians: a new take on TAM. Med Care Res Rev 2007;64(06): 650-672 
e40 Physicians' Estimates of Electronic Prescribing Kivekäs et al.

36 Sicotte C, Taylor L, Tamblyn R. Predicting the use of electronic prescribing among early adopters in primary care. Can Fam Physician 2013;59(07):e312-e321

37 Gagnon MP, Ghandour K, Talla PK, et al. Electronic health record acceptance by physicians: testing an integrated theoretical model. J Biomed Inform 2014;48:17-27

38 Islam A, Azad N, Mäntymäki M, Islam S. TAM and E-learning Adoption: A Philosophical Scrutiny of TAM, Its Limitations, and Prescriptions for E-learning Adoption Research. Berlin, Heidelberg: Springer; 2014

39 Rogers R, Peres Y, Müller W. Living longer independently - a healthcare interoperability perspective. Elektrotech Inform 2010; 127(7-8):206-211

40 Motulsky A, Lamothe L, Sicotte C. Impacts of second-generation electronic prescriptions on the medication management process in primary care: a systematic review. Int J Med Inform 2013;82 (06):473-491

41 Hyppönen H, Hännikäinen K, Pajukoski M, Ruotsalainen P, Salmivalli L, Tenhunen E. Evaluation of the National Electronic Prescribing Pilot II (2005-2006). STAKES, Reports 11/2006. Helsinki, 2006
42 Hair J, Black W, Babin B, Anderson R. Multivariate Data Analysis. A Global Perspective. 7th ed. Upper Saddle River, NJ: Pearson Education; 2010

43 Ministery of Social Affairs and Health. Information to Support Well-Being and Service Renewal. e-Health and e-Social Strategy 2020. Helsinki: Edita Prima; 2015

44 Saeed KA, Abdinnour-Helm S. Examining the effects of information system characteristics and perceived usefulness on post adoption usage of inormation systems. Inf Manage 2008; 45:376-386

45 Gururajan R. Organizational factors and technological barriers as determinants for the intention to use wireless handheld technology in healthcare environment: an Indian case study. In: Khoumbati K, Kumar Dwivedi Y, Srivastava A, Lal B, eds. Handbook of Research on Advances in Health Informatics and Electronic Healthcare Applications. Global Adoption and Impact of Information communication Technologies. Hershey, PA: Medical Information Science Reference; 2010:109-123

46 Miller GA, Chapman JP. Misunderstanding analysis of covariance. J Abnorm Psychol 2001;110(01):40-48 